\title{
Design of a rotational type vibration absorber
}

\section{Diseño de un absorbedor de vibraciones tipo rotacional}

VÁZQUEZ-GONZÁLEZ, Benjamín†๋*, JIMÉNEZ-RABIELA, Homero and RAMÍREZ-CRUZ, José Luis

Universidad Autónoma Metropolitana, Azcapotzalco Unit, Division of Basic Sciences and Engineering, Department of Energy, Mexico.

ID $1^{\text {st }}$ Author: Benjamín, Vázquez-González / ORC ID: 0000-0002-9030-5662, Researcher ID Thomson: S-2417-2018, CVU CONACYT ID: 25749

ID $1^{\text {st }}$ Co-author: Homero, Jiménez-Rabiela / ORC ID: EfLkjm13091998, Researcher ID Thomson: S-2299-2018, CVU CONACYT ID: 123386

ID $2^{\text {nd }}$ Co-author: José Luis, Ramírez-Cruz / ORC ID: 0000-0003-0762-2630, Researcher ID Thomson: G-3405-2019, CVU CONACYT ID: 921268

DOI: $10.35429 / J M E .2020 .13 .4 .16 .22$

Received January 20, 2020; Accepted June 30, 2020

\begin{abstract}
Mechanical vibration absorbers are mechanical subsystems capable of developing an oscillatory movement, which dynamically compensates for the vibratory motion developed by a mechanical system of interest, which is affected by an action that can produce a movement that directly affects it in a non-desirable way. The system of interest is called the primary system and the absorber is called the secondary system. The way in which both systems interact establishes the conditions in which absorption will take place. Traditional absorbers are made up of systems coupled by means of an elastic element, they can also have viscous type coupling and very complex couplings can be presented by elastic and viscous type combinations. The objective of the present work is to design a rotational type vibration absorber, in which the interaction between both mechanical systems is developed by contact by rotation without sliding and elastic coupling. Euler-Lagrange equations are used to obtain the mathematical model of the system. One of the main characteristics of the rotary absorber is that the absorber can be designed to achieve small amplitudes of the displacement of its center of mass, but large displacements. Results are presented in numerical simulation.
\end{abstract}

\section{Resumen}

Los absorbedores de vibraciones mecánicas son subsistemas mecánicos capaces de desarrollar un movimiento oscilatorio, que compensa dinámicamente el movimiento vibratorio que desarrolla un sistema mecánico de interés, el cual se ve afectado por una acción que puede producir un movimiento que incida directamente sobre él de manera no deseada. El sistema de interés se denomina sistema principal y al absorbedor se le denomina sistema secundario. La forma en que ambos sistemas interactúan establece las condiciones en las que la absorción se desarrollará. Los absorbedores tradicionales se conforman por sistemas acoplados por medio de un elemento elástico, también pueden tener acoplamiento de tipo viscoso y se pueden presentar acoplamientos muy complejos por combinaciones elásticas y de tipo viscoso. En el presente trabajo se tiene por objetivo diseñar un absorbedor de vibraciones tipo rotacional, en el que la interacción entre ambos sistemas se desarrolla por contacto por rotación sin deslizamiento y acoplamiento elástico. Se utilizan las ecuaciones de Euler-Lagrange para obtener el modelo matemático del sistema. Una de las principales características del absorbedor por rotación, es que el absorbedor puede ser diseñado para alcanzar pequeñas amplitudes del desplazamiento de su centro de masa, pero grandes desplazamientos. Se presentan resultados en simulación numérica.

Sistemas lineales, Absorción de vibraciones, Sintonización

\footnotetext{
* Correspondence to the Author (Email: bvg@ correo.azc.uam.mx)

$\dagger$ Researcher contributing as first author.
} 


\section{Introduction}

Vibration absorbers are devices designed and used to reduce the vibratory effects that occur or act in any system, machine or element thereof, these vibrations can be harmful due to the repetitive effect, which can cause failure in materials or wear in the elements of the machines.

Carter mentions that the studies on vibration absorbers began with the developments made by Den Hartog, and the coupling between two masses joined by means of an elastic device or spring was considered.

One of the later studies was the one carried out by Roberson, which sought to extend the bandwidth of the action of the absorber of this type.

It has also been sought to extend Den Hartog's results to larger systems, Bulent and Royston, present the results of their work.

Huang and Lin, present in their study four types of absorbers in order to improve the absorption capacity.

Harik and Issa have continued to search for optimal parameters.

In the present work, an alternative configuration is proposed that consists of evaluating the absorption by means of direct contact by rotation without sliding, which occurs between two elements of a vibratory system, it also includes elastic interaction between both bodies.

The dynamic coupling that exists between the elements of the vibratory system is the condition that allows the absorption of vibrations or the tuned energy exchange, this means that there is a correlation between the movement of each body.

For the present case, dynamic coupling consists of the mutual interaction of accelerations and displacements, together with the participation of an element of the system that allows the dynamic tuning of movements, and this favors the flow of mechanical energy, which produces that the actions that are applied directly to the primary system, indirectly affect the secondary or absorber system.

\section{Rotational absorber}

Figure 1 shows a diagram that illustrates the position of each of the elements of the mechanical system. It is a forced two-degree-offreedom system. The excitation is harmonic and the system has no damping, the primary system is designated by $\mathrm{m}_{1}$, the absorber is designated by $\mathrm{m}_{2}$.

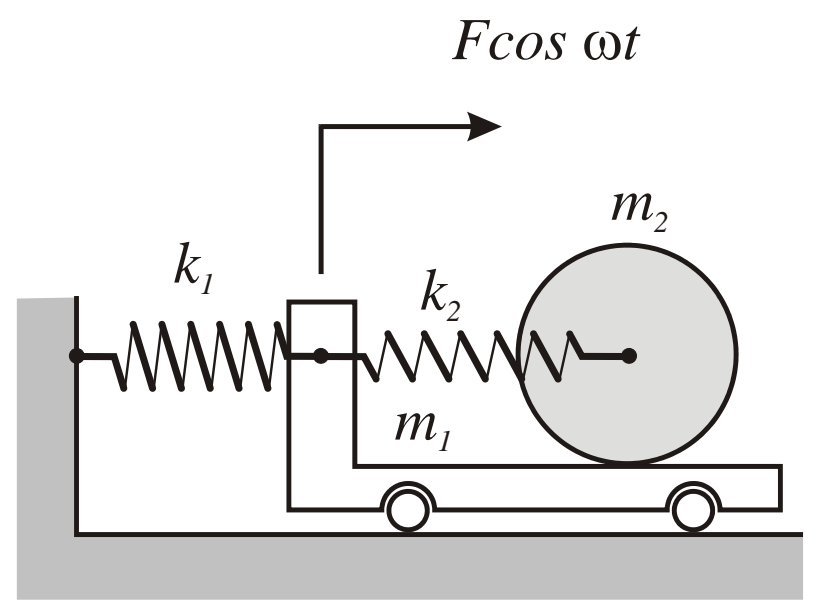

Figure 1 Scheme illustrating the configuration of the primary system, represented by $\mathrm{m} 1$ and its absorber, represented by $\mathrm{m}_{2}$

The movement of the platform or primary system is of the oscillatory type, there is an external force that directly affects said platform, which is of the harmonic type $F(t)=F$ $\cos \omega t$, where $\mathrm{F}$ represents the magnitude of the force expressed in Newtons and it is constant. $\omega$ corresponds to the angular frequency of the excitation movement, which is expressed in $\mathrm{rad} / \mathrm{s}$. The platform induces an oscillatory movement to the absorber, which also oscillates, in this case a rotational oscillation develops. The objective is to determine the parameters $\mathrm{m}_{2}$ and $\mathrm{k}_{2}$, in such a way that although the force acts directly on the platform, it moves as little as possible and the cylinder or disk absorbs all the movement energy, reducing the movement in the main system.

Unlike the typical vibration absorber, defined by two bodies that are joined by means of a spring, and each body moves with respect to the same fixed reference, the present system has the characteristic of establishing couplings defined by the relative position between them. bodies, in turn there is also an elastic coupling, due to the spring $\mathrm{k}_{2}$, which joins both bodies. 
The problem is of particular interest because because the absorber is of the rotational type, it is possible to determine many relationships between $\mathrm{m}_{2}$ and $\mathrm{k}_{2}$, but the form of absorber is very important, because many rotational absorbers can be established because a free parameter is the radius $r$ of the cylinder or absorber. With the above, it is possible to have a long relative displacement between both bodies, but a small displacement of the center of mass of the absorber, the present absorber has the characteristic of being compact.

\section{Dynamic model of the rotational absorber}

In Figure 2, the diagram that identifies the variables of the movement is presented.

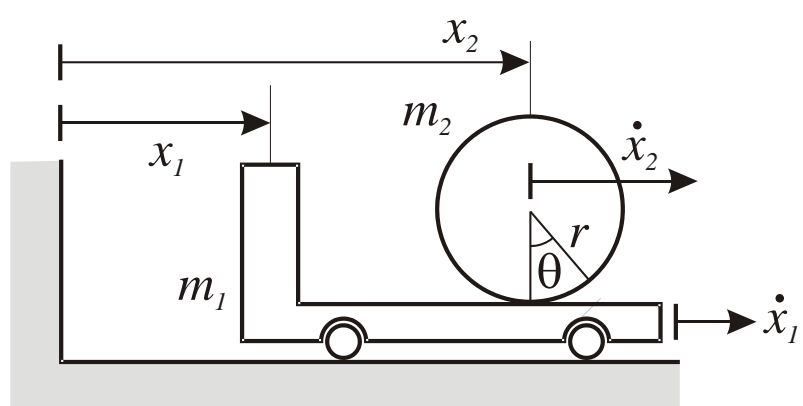

Figure 2 This Figure illustrates the position and velocity variables of the elements of the mechanical system

The displacement of the cylinder when rotating is quantified by the relation,

$\mathrm{s}=\mathrm{r} \theta$

On the other hand, the relative movement between both bodies is quantified with the relation,

$\mathrm{s}=\mathrm{x}_{2}-\mathrm{x}_{1}$

so,

$\theta=\frac{\mathrm{x}_{2}-\mathrm{x}_{1}}{r}$

and drifting in time, it turns out

$\dot{\theta}=\frac{\dot{\mathrm{x}}_{2}-\dot{\mathrm{x}}_{1}}{r}$

The previous variables are necessary to determine the kinetic energy $\mathrm{T}$ of the system, that is,

$\mathrm{T}=\frac{1}{2} \mathrm{~m}_{1} \dot{\mathrm{x}}_{1}^{2}+\frac{1}{2} \mathrm{~m}_{2} \dot{\mathrm{x}}_{2}^{2}+\frac{1}{2} \mathrm{I}\left(\frac{1}{2} \frac{\left(\dot{\mathrm{x}}_{2}-\dot{\mathrm{x}}_{1}\right)}{\mathrm{r}}\right)^{2}$
Where I represents the moment of inertia of the disk or cylinder.

The potential energy $\mathrm{V}$ of the system is,

$\mathrm{V}=\frac{1}{2} \mathrm{k}_{1} \mathrm{x}_{1}^{2}+\frac{1}{2} \mathrm{k}_{2}\left(\mathrm{x}_{2}-\mathrm{x}_{1}\right)^{2}$

The Lagrangian $\mathrm{L}$ is determined by the expression, $\mathrm{L}=\mathrm{T}-\mathrm{V}$, resulting,

$\mathrm{L}=\frac{1}{2} \mathrm{~m}_{1} \dot{\mathrm{x}}_{1}^{2}+\frac{1}{2} \mathrm{~m}_{2} \dot{\mathrm{x}}_{2}^{2}+\frac{1}{4} \mathrm{~m}_{2}\left(\dot{\mathrm{x}}_{2}-\dot{\mathrm{x}}_{1}\right)-\frac{1}{2} \mathrm{k}_{1} \mathrm{x}_{1}^{2}-\frac{1}{2} \mathrm{k}_{2}\left(\mathrm{x}_{2}-\mathrm{x}_{1}\right)^{2}$

The Euler-Lagrange equations for this system, without dissipative terms and with external excitation are,

$$
\begin{aligned}
& \frac{\mathrm{d}}{\mathrm{dt}}\left(\frac{\partial \mathrm{L}}{\partial \dot{\mathrm{x}}_{1}}\right)-\left(\frac{\partial \mathrm{L}}{\partial \mathrm{x}_{1}}\right)=\frac{\partial \Pi}{\partial \dot{x}_{1}} \\
& \frac{\mathrm{d}}{\mathrm{dt}}\left(\frac{\partial \mathrm{L}}{\partial \dot{\mathrm{x}}_{2}}\right)-\left(\frac{\partial \mathrm{L}}{\partial \mathrm{x}_{2}}\right)=0
\end{aligned}
$$

Where,

$\Pi=\mathrm{F}(\mathrm{t}) \dot{\mathrm{x}}_{1}$

From this last expression the excitation term is determined,

$\frac{\partial \Pi}{\partial \dot{x}_{1}}=\mathrm{F}(\mathrm{t})=\mathrm{F} \cos \omega \mathrm{t}$

By developing the partial and total derivatives of equations (8) and (9), together with expression (11), the following dynamic equations result,

$\left(\mathrm{m}_{1}+\frac{1}{2} \mathrm{~m}_{2}\right) \ddot{\mathrm{x}}_{1}-\frac{1}{2} \mathrm{~m}_{2} \ddot{\mathrm{x}}_{1}+\left(\mathrm{k}_{1}+\mathrm{k}_{2}\right) \mathrm{x}_{1}-\mathrm{k}_{2} \mathrm{x}_{2}=\mathrm{F} \cos \omega \mathrm{t}$

$\frac{3}{2} \mathrm{~m}_{2} \ddot{\mathrm{x}}_{2}-\frac{1}{2} \mathrm{~m}_{2} \ddot{\mathrm{x}}_{1}+\mathrm{k}_{2} \mathrm{x}_{2}-\mathrm{k}_{2} \mathrm{x}_{1}=0$

\section{Solution of the system of dynamic equations}

In this section the system of dynamic equations of the primary system and its absorber is solved.

Since the system is excited by a harmonic function, the following solutions are proposed,

$\mathrm{x}_{1}=\mathrm{A} \cos \omega \mathrm{t}$
$\mathrm{x}_{2}=\mathrm{B} \cos \omega \mathrm{t}$

Where $\mathrm{A}$ and $\mathrm{B}$ correspond to the amplitudes of the oscillatory motion of the primary and secondary system, respectively.

VÁZQUEZ-GONZÁLEZ, Benjamín, JIMÉNEZRABIELA, Homero and RAMÍREZ-CRUZ, José Luis. Design of a rotational type vibration absorber. Journal of Mechanical Engineering. 2020 
The second derivatives in time of equations (14) - (15) are,

$\ddot{\mathrm{x}}_{1}=-\omega^{2} \mathrm{~A} \cos \omega \mathrm{t}$

$\ddot{\mathrm{x}}_{2}=-\omega^{2} \mathrm{~B} \cos \omega \mathrm{t}$

By substituting the equations, from (14) to (17), in equations (12) - (13), the following algebraic system of equations results,

$$
\begin{aligned}
& \left(\left(k_{1}+k_{2}\right)-\left(m_{1}+\frac{1}{2} m_{2}\right) \omega^{2}\right) A+\left(\frac{1}{2} m_{2} \omega^{2}-k_{2}\right) B=F \\
& \left(-\frac{3}{2} m_{2} \omega^{2}+k_{2}\right) B+\left(\frac{1}{2} m_{2} \omega^{2}-k_{2}\right) A=0
\end{aligned}
$$

The system of equations (18) - (19) can be written in matrix form, the result is the following,

$\left[\begin{array}{cc}\left(\mathrm{k}_{1}+\mathrm{k}_{2}\right)-\left(\mathrm{m}_{1}+\frac{1}{2} \mathrm{~m}_{2}\right) \omega^{2} & \frac{1}{2} \mathrm{~m}_{2} \omega^{2}-\mathrm{k}_{2} \\ \frac{1}{2} \mathrm{~m}_{2} \omega^{2}-\mathrm{k}_{2} & -\frac{3}{2} \mathrm{~m}_{2} \omega^{2}+\mathrm{k}_{2}\end{array}\right]\left[\begin{array}{l}\mathrm{A} \\ \mathrm{B}\end{array}\right]=\left[\begin{array}{l}\mathrm{F} \\ 0\end{array}\right]$

Although the system of equations is simple, the solutions are extensive and the information content is useful in designing the absorber.

The solution of the system of equations (20) is as follows,

$$
\begin{aligned}
& A=\frac{\left(3 \mathrm{~m}_{2} \omega^{2}-2 \mathrm{k}_{2}\right) \mathrm{F}}{\Delta} \\
& \mathrm{B}=\frac{\left(\mathrm{m}_{2} \omega^{2}-2 \mathrm{k}_{2}\right) \mathrm{F}}{\Delta}
\end{aligned}
$$

Where

$\Delta=\left(3 \mathrm{~m}_{1} \mathrm{~m}_{2}+\mathrm{m}_{2}^{2}\right) \omega^{4}-\left(3 \mathrm{k}_{1} \mathrm{~m}_{2}+2 \mathrm{k}_{2} \mathrm{~m}_{1}+2 \mathrm{k}_{2} \mathrm{~m}_{1}\right) \omega^{2}+2 \mathrm{k}_{1} \mathrm{k}_{2}$

\section{Vibration absorber design}

The design of the absorber is carried out from equation (21), since it is intended that the amplitude is as low as possible, the dynamic parameters of the absorber can be chosen for this purpose. The design in this way is done by imposing the following condition,

$A=\frac{\left(3 \mathrm{~m}_{2} \omega^{2}-2 \mathrm{k}_{2}\right) \mathrm{F}}{\Delta}=0$

Where does it come from,

$3 \mathrm{~m}_{2} \omega^{2}-2 \mathrm{k}_{2}=0$
Since $\mathrm{F} \neq 0$ and $\omega$ is a known parameter, which corresponds to the frequency of the movement that is printed on the primary system. expression,

In this way, we have the following

$$
\mathrm{m}_{2}=\frac{2 \mathrm{k}_{2}}{3 \omega^{2}}
$$

This will reduce the amplitude of the primary system for the mass $\mathrm{m} 2$ previously determined, and for the excitation frequency $\omega$ with any arbitrarily proposed value of $\mathrm{k} 2$.

Expression (26) defines the tuning parameters between the primary system and its absorber.

As mentioned in the introduction of this work, the tuning parameter corresponds to the speed of movement of both bodies, so knowing the value of this parameter, it will be allowed that before an action on the primary system, the movement of the absorber compensates said action with its own movement, reducing the action on the primary, resulting in a decrease in the amplitude of its movement.

\section{Equations in state space}

The system of dynamic equations (12) - (13) can be written in the state space according to the following change of variables,

$$
\dot{x}_{1}=\dot{y}_{1}, \dot{y}_{1}=y_{2}, \dot{x}_{2}=\dot{y}_{3}, \dot{y}_{3}=y_{4}
$$

$$
\left[\begin{array}{l}
\dot{y}_{1} \\
\dot{y}_{2} \\
\dot{y}_{3} \\
\dot{y}_{4}
\end{array}\right]=\left[\begin{array}{cccc}
0 & 1 & 0 & 0 \\
-\frac{3 k_{1}+2 k_{2}}{a} & 0 & \frac{2 k_{2}}{a} & 0 \\
0 & 0 & 0 & 1 \\
\frac{2 k_{2} m_{1}-k_{1} m_{2}}{b} & 0 & -\frac{2 k_{2} m_{1}}{b} & 0
\end{array}\right]\left[\begin{array}{l}
y_{1} \\
y_{2} \\
y_{3} \\
y_{4}
\end{array}\right]+\left[\begin{array}{c}
0 \\
\frac{3 F \cos \omega t}{a} \\
0 \\
\frac{F \cos \omega t}{a}
\end{array}\right]
$$

Where, $a=3 m_{1}+m_{2}$ y $b=3 m_{1} m_{2}+m^{2}{ }_{2}$

This way of expressing the dynamic system of equations, allows to carry out numerical simulations to determine the responses in time, both of the primary system and its absorber. 


\section{Results in numerical simulations}

This section presents the results of the experiments in numerical simulation of the vibratory mechanical system. Two cases can be distinguished. The first corresponds to the performance of the vibratory system under general conditions, that is, without determining the parameters of the absorber or tuning. Numerical simulations were performed using the Runge-Kutta-Fehlberg 2/3 method, according to Vázquez et al.

To illustrate the above, consider the following numerical values,

\begin{tabular}{|r|r|r|}
\hline $\mathrm{m}_{1}=1.5 \mathrm{~kg}$ & $\mathrm{~m}_{2}=0.3 \mathrm{~kg}$ & $\mathrm{k}_{1}=200 \mathrm{~N} / \mathrm{m}$ \\
\hline $\mathrm{k}_{2}=1000 \mathrm{~N} / \mathrm{m}$ & $\mathrm{F}=6 \mathrm{~N}$ & $\omega=10 \mathrm{rad} / \mathrm{s}$ \\
\hline
\end{tabular}

Table 1 General parameters of the vibratory mechanical system figures.

The results are described in the following

In Figure 3, the development in time of the primary system is shown, after a certain time, an approximate permanent amplitude of $\mathrm{x} 1=$ $0.3064 \mathrm{~m}$ is reached, for the data in Table 1 .

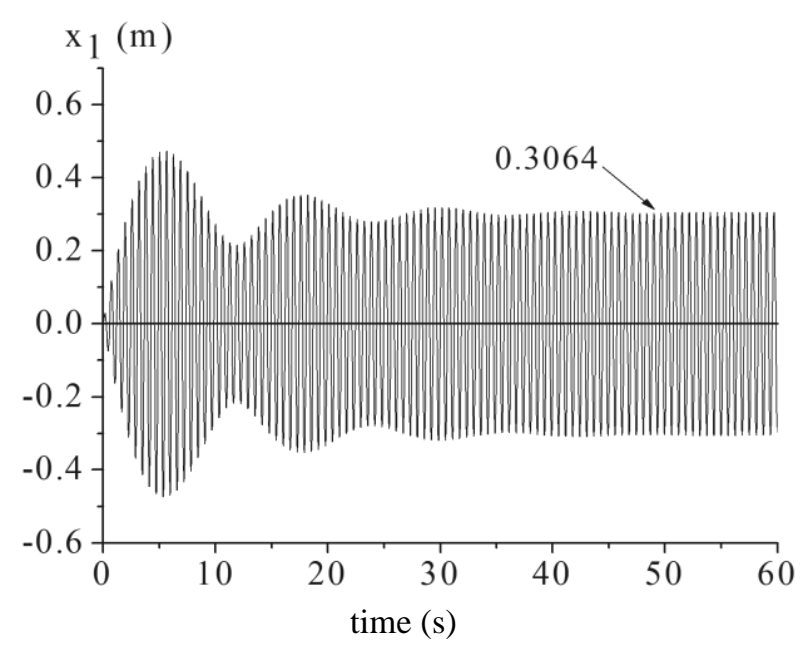

Figure 3 Response in time of the primary system for the data in Table 1, an approximate value of $\mathrm{x} 1=0.3064 \mathrm{~m}$ is reached

Figure 4 shows the performance over time of the secondary system for the parameters of Table 1 , in which the tuning condition is not considered.

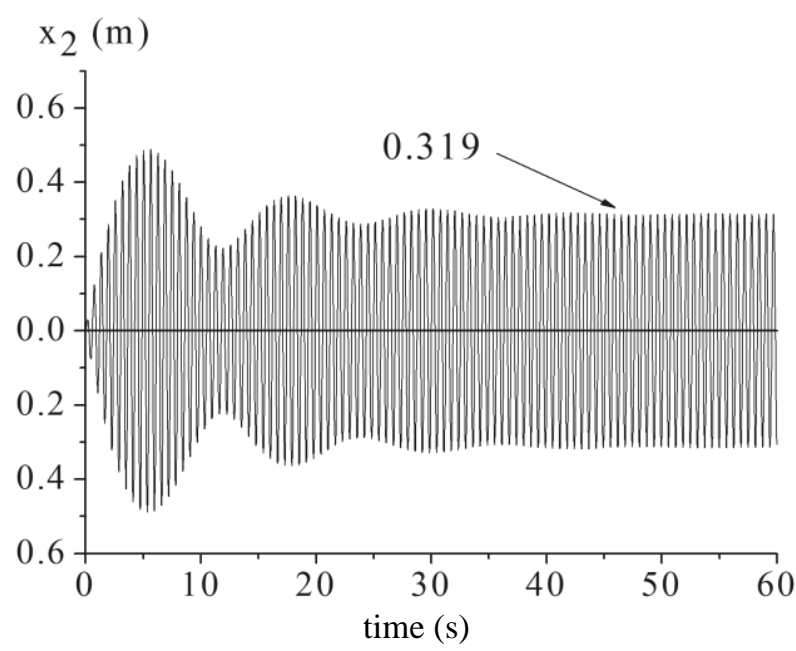

Figure 4 Absorber time response for the data in Table 1, an approximate value of $\mathrm{x} 2=0.319 \mathrm{~m}$ is reached

In this case, it is observed that a sample of the amplitude reaches a value $\mathrm{x} 2=0.319 \mathrm{~m}$.

The previous simulations are presented to observe the performance of the system as a whole, each subsystem reaches particular values, however, the tuning condition defines minimum values of the primary system.

Note the proportion of the displacements in relation to the magnitude of the applied force.

The evaluation of the amplitudes using the solutions (21) - (22) for the numerical values of Table 1, reports the following values: $\mathrm{A}=$ $0.31484 \mathrm{~m}$ and $\mathrm{B}=-0.32473 \mathrm{~m}$, which are consistent with the results in simulation.

Now the tuning condition defined by equation (26) is considered, that is, the calculation of $\mathrm{m} 2$ is performed, for the excitation frequency $\square$ and preserving the value of $\mathrm{k} 2$, in order to preserve the values of the initial parameters, without However, there is the possibility to propose some other value arbitrarily.

The results are shown in the following Table.

\begin{tabular}{|l|l|l|}
\hline $\mathrm{m}_{1}=1.5 \mathrm{~kg}$ & $\mathrm{~m}_{2}=6.6667 \mathrm{~kg}$ & $\mathrm{k}_{1}=200 \mathrm{~N} / \mathrm{m}$ \\
\hline $\mathrm{k}_{2}=1000 \mathrm{~N} / \mathrm{m}$ & $\mathrm{F}=6 \mathrm{~N}$ & $\omega=10 \mathrm{rad} / \mathrm{s}$ \\
\hline
\end{tabular}

Table 2 Design parameters of vibration absorber 
Figure 5 shows the performance over time of the primary system for the values in Table 2, it is observed that in a period, the amplitude decreases continuously, an arbitrary measurement reports a value of $\mathrm{x} 1=0.0017 \mathrm{~m}$, which represents a significant reduction in relation to the previous general case.

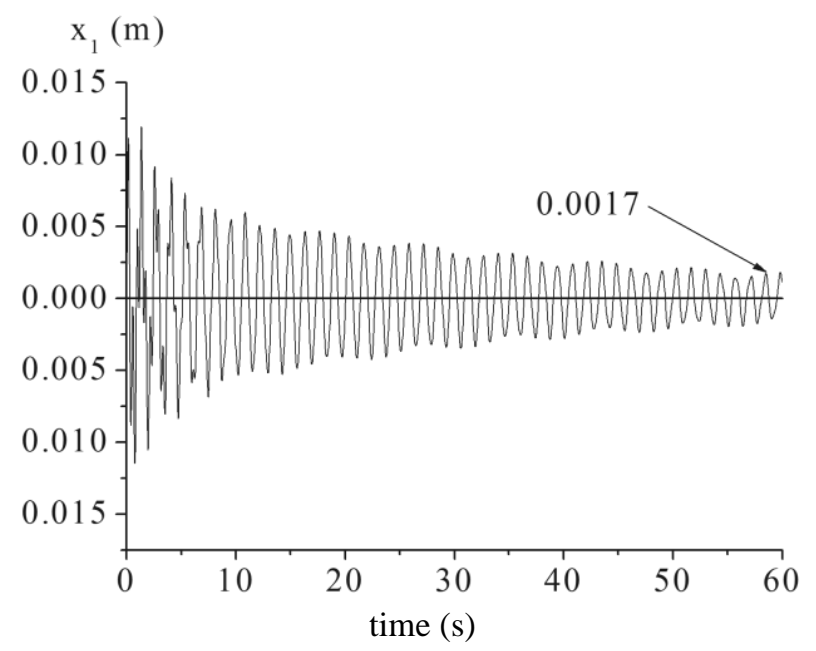

Figure 5 Response in time of the primary system for the data in Table 2, an approximate value of $\mathrm{x} 1=0.0017 \mathrm{~m}$ is reached

Figure 6 shows the development in time of the absorber for the values in Table 2, the amplitude of its movement is also much smaller in relation to the general case, however, the value of the mass is quite high in relation with the mass in Table 1, but it must be considered that it was decided to conserve the value of the spring constant $\mathrm{k} 2$. This means that you have the freedom to also modify the value of said elastic parameter, which can lead to obtaining smaller values of the absorber mass.

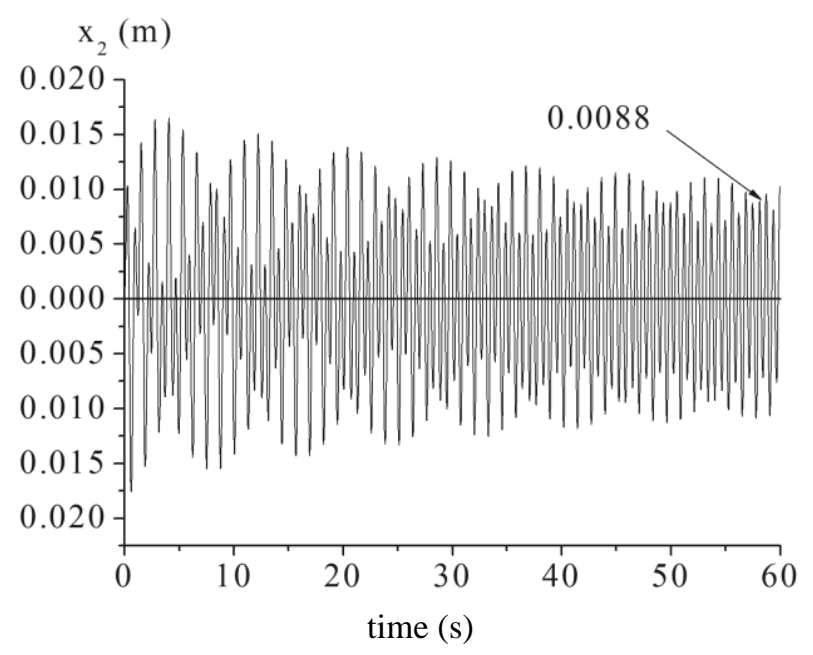

Figure 6 Absorber time response for the data in Table 2, an approximate value of $\mathrm{x} 2=0.0088 \mathrm{~m}$ is reached
Again, using the expressions that allow determining the amplitude (21) - (22), the following results are obtained for the values of Table 2, $\mathrm{A}=-6.7500 \times 10^{-8}$, and $\mathrm{B}=0.0089999$ $\mathrm{m}$.

The simulation results are also consistent with the expected values in the case of the absorber, however, it is important to note that, from the algebraic point of view, the amplitude of the primary system should be strictly $\mathrm{A}=0$, which does not result, as an effect of numerical calculation.

In each case, the negative sign refers to the direction of movement, the significant value being the magnitude.

It is convenient to make a precision between secondary system and absorber, the absorber is defined when the secondary system is determined with the parameters defined by the tuning condition (26) and presented in Table 2.

The previous results allow us to observe the decrease in the amplitude of the movement of the primary system, note that the body does not stop, it develops an oscillatory movement of very low amplitude, in turn, the amplitude of the oscillation of the secondary system is also low in relation with the overall performance, in this way it can be confirmed that the rotational absorber has fulfilled its function.

Note also that the envelope of the graph of Figure 5 is like the behavior of the damped movement, considering that the present system is undamped, in the sense of the way in which over time, the amplitude of the movement it is reducing.

\section{Acknowledgments}

The authors are grateful for the institutional support of the Universidad Autónoma Metropolitana and the Azcapotzalco Unit, in particular the Division of Basic Sciences and Engineering and the Department of Energy. 


\section{Conclusions}

In this work the parameters of a rotational vibration absorber have been determined. The rotational vibration absorber has the characteristic of being compact because the absorption movement is developed by direct contact in the main system and its primary system. Compared to the general performance, the vibration absorption is significant, a high value of the absorber mass produces a considerable reduction in the amplitude of the primary system, because the mechanical energy to maintain the movement of the absorber is also high. From the tuning condition it is possible to arbitrarily propose parameters that allow the flow of mechanical energy efficiently. The rotational vibration absorber still has the advantage of being able to establish the dimension of the absorber, because it is possible to obtain a small body of great mass.

\section{References}

Harik R. F, Issa J. S. (2015) Design of a vibration absorber for harmonically forced damped systems, Journal of Vibration and Control, 21(9). 1810-1820.

Mehmet Bulent Ozer, Thomas J. Royston. (2005) Extending Den Hartog's Vibration Absorber Technique to Multi-Degree-ofFreedom Systems. Journal of Vibration and Acoustics, 127(4), 341-350.

Robert E. Robertson. (1952) Synthesis of a nonlinear dynamic vibration absorber. Journal of the Franklin Institute 254 (3), 205 - 220.

Shyh-Chin Huang, Kao-An Lin. (2014) A New Design of Vibration Absorber for Periodic Excitation Shock and Vibration - Hindawi Publishing Corporation, 2014, 1 - 11.

Vázquez González Benjamín, Jiménez Rabiela Homero, Ramírez Cruz José Luis, Bravo Acosta Adrian Gustavo. (2019) Algunos errores numéricos en la respuesta del estado estable de sistemas mecánicos vibratorios, Revista de Ingeniería Mecánica, ECORFAN-Spain, 3 (12), $1-9$.

W. J. Carter, F. C. Liu. (1961) Steady-State Behavior of Nonlinear Dynamic Vibration Absorber. Journal of Applied, Mechanics, March 1961, 67 - 70. 